\title{
ANÁLISIS COSTO-BENEFICIO EN EL DERECHO AMBIENTAL DE LOS ESTADOS UNIDOS*
}

\author{
Richard L. Revesz
}

La toma de decisiones constituye una parte esencial de la acción gubernamental. El gobierno tiene la responsabilidad de utilizar los instrumentos a su disposición que le permitan tomar las mejores decisiones posibles. Este artículo sostiene que el análisis costo-beneficio, adecuadamente utilizado, puede mejorar las políticas ambientales y de salud pública. Para ello, se explican las razones de por qué resulta necesaria su aplicación. Además, se describen los orígenes de su incorporación en los Estados Unidos. Asimismo, se analizan algunas de las deficiencias de su aplicación actual, detallando alternativas para su corrección.

Palabras clave: análisis costo-beneficio; políticas y regulaciones ambientales; Agencia Ambiental de los EE.UU. (EPA, por sus siglas en inglés).

Richard L. Revesz. Abogado (J. D.) Yale Law School, Máster en Ciencias (MIT) e Ingeniero por Princeton University. Decano y Lawrence King Professor of Law, New York University School of Law. Miembro del Council on Foreign Relations.

* Texto presentado en el seminario "El desafío del análisis costo-beneficio ambiental” que tuvo lugar en el Centro de Estudios Públicos el 17 de junio de 2009. Agradezco a Gonzalo Moyano y a Florencia Santino por su colaboración en la preparación de este trabajo. 


\section{Introducción}

\section{F}

ste artículo se basa en el libro Retaking Rationality: How Cost-Benefit Analysis Can Better Protect the Environment and Our Health, escrito junto a Michael Livermore. En el libro sostenemos que el análisis costo-beneficio, cuando se lleva a cabo correctamente, contribuye a mejorar las políticas ambientales y de salud pública. El análisis costo-beneficio, puesto de una forma simple, implica traducir vidas humanas y hectáreas de bosques en pesos y centavos. Si bien esto puede parecernos duro e impersonal, esta herramienta es necesaria para mejorar la calidad de las decisiones que tomamos en materia regulatoria. Para salvar el mayor número de vidas y proteger de la mejor manera posible al medioambiente y a nuestra salud, necesitamos usar nuestras mejores herramientas analíticas.

Muchas veces tenemos la tentación de confiar en nuestros instintos cuando debemos tomar decisiones, como una forma de evitar el análisis económico, que, para muchos, es como hablar en otro idioma. Pero las decisiones de gobierno son mucho más complicadas que las que tomamos en nuestra vida cotidiana y, por tanto, no tenemos más opción que recurrir a herramientas analíticas complejas para poder tomar las mejores decisiones posibles. Si no usáramos estas herramientas estaríamos abandonando nuestros deberes hacia los demás, lo que de ningún modo es una respuesta legítima. Lo que tenemos que hacer es ejercer lo que se denomina "compasión estadística” y reconocer que los números en el papel representan vidas salvadas, personas que viven y respiran ${ }^{1}$.

El objetivo del análisis costo-beneficio es claro: busca maximizar los beneficios netos de una regulación. Los beneficios netos se calculan restando los costos de la regulación - como el costo de cumplir con ella, los puestos de trabajo perdidos y la disminución en el bienestar de los consumidores como consecuencia del aumento de los precios de

\footnotetext{
${ }^{1}$ Elaine Scarry ha desarrollado una comparación entre la denominada “compasión individual” y la “compasión estadística”. La primera es familiar: ver una persona que sufre, o escuchar la historia de una tragedia, nos mueve a una acción. Por su parte, la compasión estadística parece ajena: escuchamos sólo un conjunto de números pero debemos comprender "la realidad concreta incluida allí”. La compasión individual deriva de nuestra naturaleza social y puede ser vinculada directamente al cerebro humano. La compasión estadística nos llama a utilizar nuestro poder de razonamiento más alto a fin de extender nuestra compasión natural a la tarea de resolver problemas más abstractos pero no por ello menos reales (Scarry, 1996).
} 
las mercaderías reguladas - de los beneficios netos — como las vidas salvadas o protegidas de la enfermedad o la invalidez, la preservación de la naturaleza, la creación de empleos o de oportunidades recreativas. En la práctica, por supuesto, la cuestión de contabilizar los costos y los beneficios enseguida se vuelve muy complicada. Pero la idea central es simple e intuitiva.

\section{2. ¿Por qué el análisis costo-beneficio?}

\subsection{Escasez y eficiencia}

Suele preguntarse por qué necesitamos recurrir al análisis costobeneficio. La respuesta es fácil: vivimos en un mundo de recursos escasos y hay algunos problemas sociales que no podríamos resolver, ni aunque gastáramos hasta el último centavo que tenemos. Pensemos por ejemplo en el caso de los contaminantes que tienen efectos adversos para la salud cualquiera sea su concentración. Si quisiéramos eliminar completamente los riesgos asociados a estos contaminantes, tendríamos que eliminar o capturar cada una de las moléculas de estas sustancias que existan en el medioambiente -lo que claramente es una tarea imposible. Pero aun cuando es imposible alcanzar un nivel de riesgo cero, siempre podemos reducir el riesgo un poco más. ¿Cómo decidimos dónde parar de gastar dinero? El análisis costo-beneficio nos ayuda a gastar dinero hasta el punto en el que el último centavo invertido nos proporcione un centavo de reducción del riesgo. Si gastáramos más estaríamos pagando por más de lo que recibimos. Pero si gastáramos menos, estaríamos renunciando a reducciones de riesgo que son socialmente deseables.

Cuando se considera la adopción de cualquier regulación destinada a aumentar la eficiencia económica, un funcionario responsable debería estimar sus costos y beneficios. De otra forma, es imposible saber en qué punto dejar de gastar dinero para lograr ese objetivo y empezar a gastarlo para lograr otros. Pero aun cuando la regulación está motivada en objetivos distintos de la eficiencia —la protección de derechos, la redistribución de la riqueza, o el cumplimiento de obligaciones moraleses importante considerar su impacto económico ${ }^{2}$. El análisis costo-beneficio también ayuda a que los funcionarios sean responsables por las decisiones que toman porque las vuelve más transparentes.

${ }^{2} \mathrm{Al}$ respecto, véase Holmes y Sunstein (2000). 
De una forma u otra el análisis costo-beneficio siempre está presente cuando tomamos decisiones. De hecho, la mayoría de las decisiones políticas involucra algún tipo de análisis costo-beneficio, aunque no sea más que en una forma primitiva, que ni siquiera considera algunos costos (como los que afectan a los grupos que son políticamente más débiles), y les da un peso indebido a algunos beneficios (como los que están dirigidos a quienes tienen el poder político). Pero cuando hacemos una evaluación exacta de los costos y los beneficios reales de la decisión, las distorsiones de la política, como los acuerdos a puertas cerradas y el lobby de los grupos de interés, se vuelven evidentes. Y cuando las malas decisiones son medidas conforme a una escala objetiva, es más fácil detectarlas y actuar en consecuencia.

Volvamos por un momento al caso de los contaminantes que tienen efectos adversos para la salud cualquiera sea su concentración. Un típico ejemplo de estos contaminantes son los carcinógenos. Como no existe una concentración en la que el riesgo para la salud sea igual a cero, cuando regulamos estas sustancias tenemos que decidir qué nivel de riesgo vamos a considerar aceptable. En los Estados Unidos la decisión típica es entre una probabilidad de uno en un millón, y una probabilidad de uno en cien mil de morir a causa de la exposición al contaminante. ¿Qué nivel deberíamos elegir? El no considerar las consecuencias de esta decisión tiene que resultarnos poco atractivo. Y una vez que consideramos las consecuencias estamos sopesando los costos de una regulación más estricta versus un mayor número de vidas salvadas, que es exactamente lo que hace el análisis costo-beneficio. Del mismo modo, cuando elegimos cierto nivel de riesgo, estamos de forma implícita asignándole un valor a la vida humana. Cuando dejamos de reducir el riesgo por los costos involucrados, estamos definiendo cuánto estamos dispuestos a pagar por las vidas salvadas. El análisis costo beneficio sólo hace que estas decisiones se vuelvan explícitas y sean consistentes con el resto de las regulaciones.

\subsection{Transparencia}

El dinero que gastan los gobiernos se contabiliza en los presupuestos. Como ciudadanos somos plenamente conscientes de cuánto pagamos de impuestos cada año. Sin embargo, los presupuestos y las cargas impositivas no nos muestran los costos económicos que impli- 
can para nosotros las decisiones adoptadas por el gobierno. Estos costos son más difíciles de determinar porque afectan a individuos y empresas privadas en lugar de al gobierno. Sin algún tipo de análisis costo-beneficio, las regulaciones son equivalentes a gastos de gobierno no-contabilizados y no-contabilizables. Es importante que quienes toman decisiones sepan cuánto dinero están gastando y cuáles son los resultados que están comprando con ese dinero. Del mismo modo que los efectos ambientales de las acciones del gobierno tienen que contabilizarse en un estudio de impacto ambiental, los efectos económicos también tienen que ser reconocidos.

\subsection{Razones institucionales}

Otra razón por la cual el análisis costo-beneficio es una herramienta útil es que le da estructura a la vasta discreción que tienen los organismos de gobierno. En una democracia ideal, los ciudadanos, o sus representantes, hacen las leyes y determinan su cumplimiento. Pero este enfoque es imposible en una sociedad tan compleja como la nuestra. Para poder regular la economía de Estados Unidos necesitamos un ejército de burócratas, científicos, abogados y economistas que recopilan y procesan información y toman decisiones en consecuencia. Dada la naturaleza técnica de muchas de nuestras decisiones regulatorias, los burócratas y expertos del gobierno ejercen un poder sustancial sobre nuestras vidas. Sin embargo, podemos usar el análisis costo-beneficio para asegurarnos de que sus decisiones estén basadas en un análisis razonado y no, por ejemplo, en la decisión caprichosa de un funcionario público o en el lobby de algún grupo de interés.

\section{Críticas al análisis costo-beneficio}

\subsection{Transformación en commodities}

No obstante lo anterior, el análisis costo-beneficio ha recibido críticas $^{3}$. Tal vez el argumento más importante en su contra es que convierte a ciertos bienes en commodities. Algunos opositores sostienen

${ }^{3}$ Algunas de las críticas al análisis costo-beneficio han sido efectuadas por Adler y Posner (2006), quienes discuten los ciclos creados por preferencias cambiantes. Otras críticas han sido planteadas por Kennedy (1981), quien argumenta que la indetermina- 
que el análisis costo-beneficio "pone un valor monetario" a la vida humana y a otro tipo especial de bienes como las áreas silvestres ${ }^{4}$. Pero estas críticas en realidad confunden la acción de poner un precio con convertir dichos bienes en commodities. Poner un precio es la forma más efectiva de reunir información y distribuir nuestros recursos escasos de forma tal de obtener el mayor beneficio posible. El hecho de convertir a ciertos bienes en commodities tiene que ver con el significado social de la acción de poner un precio: el miedo de que el hecho de asignar un precio a las buenas cosas de la vida no nos deje ver su valor inherente ${ }^{5}$. Sin embargo, muchas cosas que apreciamos se pueden comprar y vender, incluyendo nuestras mascotas, casas, obras de arte, servicios médicos, anillos de compromiso y la preservación de la naturaleza.

\subsection{Certeza científica}

Otra de las críticas que ha recibido el análisis costo-beneficio es que crea la ilusión de certeza científica, cuando en realidad no la tiene. Es verdad que el análisis costo-beneficio tiene el aura de la exactitud matemática. Y también es cierto que el análisis costo-beneficio debe inevitablemente incorporar la incertidumbre. Por ejemplo, en el caso de la regulación de una sustancia contaminante, nunca podemos estar ciento por ciento seguros de los efectos que esa sustancia tiene en la salud, ni de cuáles van a ser los efectos económicos si la prohibimos. Algunas personas sostienen que esta incerteza vuelve al análisis costobeneficio una herramienta sin valor 6 . Sin embargo, el análisis costobeneficio de la regulación, realizado de forma apropiada, nos puede ayudar a cuantificar esas áreas de incertidumbre, mejorando el proceso de toma de decisiones. De hecho, el análisis costo-beneficio es espe-

ción amenaza la coherencia del análisis costo-beneficio; Sinden (2005), en el mismo sentido de Kennedy. Sunstein (2006), por su parte, ha argumentado que la maximización del beneficio económico neto no es moralmente significante. Estos problemas formales son interesantes en un sentido teórico, pero no son suficientes para argumentar que el análisis costo-beneficio no puede ser de utilidad. Sin embargo, todos estos puntos son complejos y no serán expuestos en este artículo.

${ }^{4}$ Véase Ackerman y Heinzerling (2004), así como Kelman (1981).

${ }^{5}$ Para una referencia al "fetichismo" respecto a los commodities en la teoría marxista, véase Marx (1867).

${ }^{6}$ En palabras de Michael Oppenheimer, ex científico jefe del Environmental Defense Fund (EDF), "Parece como si estuvieras balanceando grandes incertidumbres, por lo que no puedes tomarlo seriamente". Entrevista con Michael Oppenheimer, profesor de Geociencias y Asuntos Internaciones, citada en Revesz y Livermore (2008: 14). 
cialmente útil para hacer frente a los casos donde no tenemos toda la información necesaria para tomar una decisión, toda vez que nos ayuda a clarificar los contornos de nuestra incertidumbre y la distribución de los posibles resultados, aumentando de ese modo nuestra capacidad de tomar decisiones inteligentes frente a lo desconocido.

\subsection{Distribución de beneficios}

Una tercera crítica al análisis costo-beneficio es que distribuye de forma injusta los beneficios de la regulación. Este ataque se centra en realidad en una de sus premisas, que es que el valor de una regulación puede ser medido en base a lo que las personas están dispuestas a pagar por recibir su beneficio. El problema es que las amplias inequidades en la distribución de la riqueza hacen que lo que las personas están dispuestas a pagar no dependa necesariamente del bienestar que la regulación les proporciona —una persona de bajos recursos probablemente esté dispuesta a pagar muy poco por un beneficio que sin embargo mejoraría considerablemente su calidad de vida. Por lo tanto, el uso de la "disposición a pagar" como una forma de medida puede llevar a que se desvíen recursos hacia regulaciones que no maximicen el bienestar, o que favorezcan a los intereses de los ricos por sobre el de los pobres. El problema detrás de esta crítica es la brecha existente entre ricos y pobres, y no el análisis costo-beneficio. Pero independientemente de eso, el análisis costo-beneficio fue modificado en la práctica para tener en cuenta las diferencias en la distribución de la riqueza. Por ejemplo, el valor del beneficio que se asigna a las regulaciones que salvan vidas es el mismo, sin importar cual sea la población beneficiada. Llevado a cabo de esta manera, el análisis costo-beneficio no evalúa las regulaciones de acuerdo a la población afectada, sino que se usa un valor promedio derivado de toda la población y de este modo trata a todas las personas de la misma manera.

\subsection{Parias regulatorios}

Una crítica final es que el análisis costo-beneficio puede producir parias regulatorios ${ }^{7}$. Las regulaciones que benefician a algunos a

${ }^{7}$ Este argumento se vincula con uno efectuado por John Hart Ely en su libro Democracy and Distrust. Al respecto, véase Ely (1980). 
expensas de otros pueden pasar la prueba de costo-beneficio. Sobre un gran número de regulaciones, estas diferencias generalmente se compensan cuando los beneficiarios de una regulación sufren las cargas de otra. Pero puede suceder que sistemáticamente un grupo específico soporte las cargas de las regulaciones adoptadas. Y si un grupo recibe menos de lo que contribuye, mientras que se le pide que pague una y otra vez por los beneficios regulatorios que van a recibir otros, podríamos pensar que el sistema es injusto.

Esta crítica es poderosa, pero no invalida el uso del análisis costo-beneficio. Lo que sugiere, en realidad, es la necesidad de realizar mayores estudios para asegurar que los impactos del sistema regulatorio sean justos en términos distributivos. Y si fuera necesario, tendríamos que redistribuir la riqueza de la sociedad de una forma más igualitaria a través de, por ejemplo, la transferencia de impuestos y los programas públicos. Pero nada de esto requiere que descartemos el análisis costo-beneficio.

\section{5. ¿Procedimiento maestro?}

Finalmente, muchas de las críticas al análisis costo beneficio se dirigen a los que promocionan esta técnica como un procedimiento maestro, que está por encima de cualquier otro valor. Esto en realidad constituye un abuso de la técnica. El análisis costo-beneficio es sólo una herramienta importante para las políticas públicas, que nos permite medir de forma sistemática los impactos de las regulaciones propuestas y compararlos en una escala económica. Adoptar el análisis costobeneficio como un procedimiento maestro o rechazarlo absolutamente es una falsa dicotomía. En los procesos de adopción de decisiones importantes, que insumen millones de dólares y afectan a todos los ciudadanos, tenemos que aprovechar cada una de las herramientas de que disponemos para tomar las mejores decisiones posibles.

Quienes están a favor de una mayor regulación en general van a estar complacidos con los resultados del análisis costo-beneficio, cuando éste es llevado a cabo de manera correcta. Los beneficios de salvar vidas, preservar la naturaleza para las generaciones futuras y evitar catástrofes ambientales, cuando son calculados de la forma correcta, generalmente superan a los costos a corto plazo de la regulación. Además, el análisis costo-beneficio tiene el potencial de aumentar la 
transparencia de las agencias regulatorias, facilitar la centralización y coordinación de las acciones de gobierno y aportar racionalidad al sistema regulatorio.

\section{El análisis costo-beneficio en los Estados Unidos}

\subsection{Weidenbaum y la campaña de Reagan}

El análisis costo-beneficio ocupa un rol central en la aprobación de la regulación federal de los Estados Unidos. Uno de los mayores responsables de este rol fue Murray L. Weidenbaum, quien publicó en 1977 un análisis independiente de la regulación federal en el que sostenía que las regulaciones aprobadas por el gobierno en los años anteriores habían impuesto un costo de \$66 mil millones de dólares a la economía de los Estados Unidos ${ }^{8}$.

Weidenbaum afirmaba que si bien cierta regulación era necesaria para hacer frente a las fallas de mercado, hacía falta una desregulación sustancial que se podía lograr a través de "las metodologías desarrolladas en el campo de las finanzas públicas" incluyendo "el análisis costo-beneficio". Weidenbaum estaba convencido de que el análisis costo-beneficio podía ser usado para reducir el impacto total de la regulación en la economía, poner un freno a las nuevas regulaciones y fomentar la desregulación ${ }^{9}$.

Los argumentos antirregulación de los académicos conservadores y de la industria comenzaron a convencer a importantes funcionarios públicos de que había que hacer algo para ganar control sobre las nuevas agencias administrativas que estaban a cargo de las regulaciones ambientales y de salud y seguridad.

La campaña presidencial de Ronald Reagan responsabilizó a la regulación y a la burocracia federal por la inflación y la situación general de la economía. Y explotando la profunda ansiedad de la clase trabajadora y la clase media respecto de su futuro financiero, logró posicionar la agenda desregulatoria y el recorte de impuestos como la clave para crear empleos y mejorar la situación económica del país.

${ }^{8} \mathrm{Al}$ respecto, véase Weidenbaum y DeFina (1978), así como el artículo de Judith Miller en el $N$. Y. Times titulado: "Report by a Nader Group Measures Dollar Benefits of U. S. Regulations, Professor Defends Study”, publicado el 10 de octubre de 1979. Para un análisis previo, véase Weidenbaum (1975).

${ }^{9}$ Weidenbaum (1979). 
Un mes después de asumir la presidencia en 1981, Reagan dictó el decreto 12,291, el cual impuso un nivel de control sin precedentes sobre el aparato administrativo ${ }^{10}$. Este decreto creó la estructura para la "revisión centralizada" de las acciones de las agencias regulatorias, el cual continúa vigente en nuestros días. Según el decreto, las agencias tenían que preparar detallados análisis costo-beneficio de las propuestas de regulación que pudieran tener un impacto significativo en la economía, y si los costos esperados excedían sus beneficios la regulación no podía ser autorizada. Los funcionarios de la Oficina de Información y Asuntos Regulatorios (OIRA) controlaban todo el proceso y tenían el poder de determinar si las propuestas habían pasado o no el análisis costo-beneficio.

James Miller estuvo al frente de este organismo y fue el primer director ejecutivo del Grupo de Trabajo Presidencial para el Alivio Regulatorio. Este grupo se adjudicó la responsabilidad de "haberles ahorrado a los negocios y consumidores de los Estados Unidos unos \$150 mil millones de dólares” y tuvo un rol central en la reducción de las regulaciones ambientales y de salud y seguridad ${ }^{11}$. Fue durante estos años que los ambientalistas y otros grupos se formaron sus primeras opiniones desfavorables sobre la revisión centralizada y el análisis costo-beneficio.

Cuando Weidenbaum publicó su primer estudio sobre los costos de la regulación a mediados de la década de los setenta, Ralph Nader, un defensor de los derechos de los consumidores, respondió con su propio estudio, tratando de demostrar que los beneficios de las regulaciones superaban sus $\operatorname{costos}^{12}$. Sin embargo, esta vez los grupos pro regulación se sintieron empujados hacia una posición "anticosto-beneficio". Saul Miller, el vocero del movimiento sindicalista, dijo al momento de la promulgación del decreto: "Nuestra posición siempre fue que ... no nos gusta nada que ponga precio a la vida humana"13.

Los grupos pro regulación tenían miedo de que el análisis costobeneficio fuera un código para la desregulación, y no estaban equivocados. La Oficina de Gestión y Presupuesto (OMB) les mandaba a las

${ }^{10}$ Decreto (Executive Order) No 12,291 (46 Fed. Reg. 13,193).

${ }^{11} \mathrm{Al}$ respecto, véase el artículo de Ed Magnuson titulado "Three Steps Forward, Two Back”, publicado el 29 de agosto de 1983 en la revista Time.

12 Weidenbaum y DeFina (1978).

${ }^{13} \mathrm{Al}$ respecto, véase el artículo de Clyde Farnsworth titulado "Move to Cut Regulatory Costs Near”, publicado en el N. Y. Times, el 14 de febrero de 1981. 
agencias sus comentarios tan tarde que era casi imposible hacer algo productivo con ellos ${ }^{14}$. Y la opacidad del nuevo proceso de revisión hacía pensar que las industrias podrían eliminar regulaciones contrarias a sus intereses entre gallos y medianoche ${ }^{15}$.

Fue así como el análisis costo-beneficio quedó asociado a los grupos conservadores que estaban a favor de la desregulación y a un procedimiento secreto de la OMB que favorecía a los intereses de la industria ${ }^{16}$. La adopción de decisiones a puertas cerradas combinada con un sesgo antirregulación llevó a los grupos ambientalistas a ver al análisis costo-beneficio como un pretexto para desregular, en lugar de una herramienta analítica legítima.

Durante estos primeros tiempos se adoptaron muchas decisiones metodológicas sesgadas contra la regulación. En este contexto político es entendible que los grupos pro regulación hayan decidido oponerse al uso del análisis costo-beneficio.

\subsection{Administración de Bush padre}

La relación entre los intereses pro regulación y el análisis costobeneficio empeoró aún más durante la presidencia de Bush padre.

En 1989, el Congreso, en respuesta a los pedidos de los grupos ambientales, se negó a autorizar el financiamiento para la OIRA y a confirmar la designación del director de la agencia ${ }^{17}$. La respuesta del gobierno de Bush fue aumentar la prominencia del "Consejo de Competitividad”, un grupo liderado por el Vicepresidente Dan Quayle, quien se autoproclamaba como un "fanático de la desregulación"18. El enfoque del Consejo fue persuadir o coaccionar a las agencias para que relajaran las cargas regulatorias sobre la industria y el comercio "sin dejar huellas ... en el resultado de su intervención”19. Lo que convenció todavía más a los ambientalistas de que no recibirían un trato justo.

Si bien el Congreso demócrata trató de poner a la OIRA bajo el control de funcionarios menos motivados políticamente, generando la

${ }^{14}$ Sobre este punto, véase Elliot (1994).

${ }^{15}$ Véase Olson (1984).

${ }^{16}$ Véase la nota al pie 62 en Revesz y Livermore (2008: 201).

${ }^{17} \mathrm{Al}$ respecto, véase Shane (1995).

${ }^{18}$ Véase el artículo de Bob Woodward y David Broker titulado "Quayle’s Quest: Curb Rules, Leave No Fingerprints”, publicado en el Washington Post, el 9 de enero de 1991, en A1.

${ }^{19}$ Ibíd. 
esperanza de que el análisis costo-beneficio pudiera ser usado como una herramienta neutral, esto no bastó para contrarrestar las políticas de la administración Bush. Y el análisis costo-beneficio siguió fuertemente asociado con un movimiento sesgado contra la regulación y demasiado ansioso por ceder a las demandas de la industria a expensas del medio ambiente y de la salud y seguridad de los estadounidenses.

\subsection{Administración Clinton}

Cuando Clinton fue elegido Presidente en 1992, muchos esperaron que abandonara el proceso de "revisión ejecutiva" establecido durante el gobierno de Reagan ${ }^{20}$. Pero Clinton vio en este proceso una oportunidad de ejercer un control sustancial sobre las agencias regulatorias, que tenían un papel cada vez más importante dentro del gobierno. Y en 1993 promulgó su propio decreto, por el que se mantuvo la estructura del proceso de revisión de regulaciones y se continuó con la revisión de las “acciones regulatorias significativas” a cargo de la OIRA ${ }^{21}$.

Sin embargo, como una forma de dar respuesta a las críticas a la OIRA, Clinton estableció mayores requisitos de transparencia ${ }^{22}$, hizo hincapié en la necesidad de tener en cuenta los "impactos distributivos" y la "equidad” en el análisis costo-beneficio ${ }^{23}$, estableciendo vencimientos en el proceso de revisión que evitaban que la OIRA demorara de forma permanente la implementación de las regulaciones ${ }^{24}$.

Podríamos decir que con estas medidas Clinton quiso dar el mensaje de que la revisión centralizada y el análisis costo-beneficio podían ser herramientas neutrales ${ }^{25}$. Sin embargo, este mensaje tuvo

${ }^{20} \mathrm{Al}$ respecto, véase Pildes y Sunstein (2005).

${ }^{21}$ Decreto (Executive Order) No 12,866, Sección 2(f) (58 Fed. Reg. 51,735 (1993)) ("acción regulatoria significativa significa cualquier acción regulatoria que probablemente se transformará en una norma que pueda ... tener un efecto anual en la economía de \$100 millones o más”).

22 Ibíd., sección 6(b)(4).

${ }^{23}$ Ibíd., sección 1(a).

${ }^{24}$ Ibíd., sección 6(b)(2).

${ }^{25}$ Esta postura fue más tarde apoyada en una publicación escrita después del término de la administración Clinton por Elena Kagan, ex asesora para el Presidente en política interna y directora del Consejo para Política Interior, en la Revista de Derecho de Harvard. Ella detallaba cómo Clinton utilizó el estado administrativo para alcanzar sus propios fines progresistas políticos. En su opinión, la revisión centralizada del costobeneficio constituye una de las herramientas disponibles para los presidentes — progresistas y conservadores por igual- para dejar su sello en el aparato burocrático. 
una fría recepción entre los grupos pro regulación, que decidieron no involucrarse en el desarrollo de la metodología ${ }^{26}$.

Sally Katzen, que estaba al frente de la OIRA, recuerda que la administración Clinton era "receptiva respecto de las posiciones de los ambientalistas" sobre cómo debía realizarse el análisis costo-benefi$\mathrm{cio}^{27}$. Pero mientras la industria y otros intereses antirregulación hacían lobby de forma constante para que se adoptaran determinadas metodologías que los favorecían, los ambientalistas se mantuvieron en la posición "no nos gusta el análisis costo-beneficio, y punto".

Los ambientalistas se sentían mal equipados (y en cierta medida lo estaban) para contribuir a las decisiones técnicas del análisis costobeneficio. Sin embargo, los grupos ambientalistas lograron cambios en foros donde inicialmente tenían una desventaja comparativa, por lo que esto no podía ser toda la respuesta. Al menos una parte del problema consistía en que hacer lobby para lograr cambios metodológicos específicos hubiera significado violar la posición general de los grupos ambientalistas. Aun argumentar de una manera alternativa equivalía a decir "no nos gusta el análisis costo-beneficio, pero si lo van a hacer, ésta es la forma en la que deberían hacerlo” y podía ser visto como un aval tácito.

Otra importante barrera a la participación en el debate metodológico fue el número de grupos pro regulación que expresaban su posición en términos estrictamente morales, apuntando, por ejemplo, a los problemas que creaba la valuación de la vida humana. Otros más pragmáticos reconocían que no era posible gastar todo el capital social para prevenir la mortalidad prematura ${ }^{28}$. Pero la existencia de grupos que tenían una posición fuerte en contra del análisis costo-beneficio, que defendían en términos morales, hacía más difícil para los grupos más pragmáticos involucrarse en la discusión. Como resultado, aun cuando los grupos ambientalistas eran bienvenidos a dar su opinión, se autoexcluyeron del proceso.

En los primeros tiempos de la administración Clinton, el Congreso republicano, elegido en 1994, impulsó la asociación del análisis

${ }^{26}$ Entrevista a Sally Katzen, ex Subdirectora para Administración, citada en Revesz y Livermore (2008: 32).

${ }^{27}$ Ibíd.

${ }^{28}$ Entrevista a Wesley Warren, director de programas de NRDC, citada en Revesz y Livermore (2008: 35). 
costo-beneficio con la agenda antirregulación. Durante varios años se presentaron proyectos de ley que para aprobarse hubieran requerido que las agencias administrativas realizaran evaluaciones de riesgo y análisis costo-beneficio para todas las regulaciones propuestas, ampliando considerablemente el ámbito de aplicación del decreto de Clinton. Aquí los grupos ambientalistas ganaron algunas batallas, logrando impedir la aprobación de estos proyectos. Pero estas victorias llevaron a que los grupos pro regulación se atrincheraran en su posición contra el análisis costo-beneficio.

Mientras los grupos pro regulación luchaban contra el debilitamiento general de las leyes ambientales y de salud y seguridad, los académicos antirregulación trabajaban para desarrollar argumentos contra la regulación y a favor de sus versiones del análisis costo-beneficio. Así Robert Hahn, John Grahan y Viscusi comenzaron a investigar formas de "mejorar" el análisis costo-beneficio ${ }^{29}$. Cada vez que encontraban un cambio metodológico que consideraban favorable, presionaban a las agencias para lograr su adopción, argumentando a su favor en publicaciones académicas y en los círculos de políticas públicas. Muchos de los sesgos sustantivos del análisis costo-beneficio —algunos de los cuales discutiremos más tarde - fueron incubados durante este período.

Podríamos decir que los años de la presidencia de Clinton dieron a los intereses pro regulatorios un respiro parcial. Sin embargo, estos grupos no aprovecharon la oportunidad para desarrollar y articular su propia visión del Estado regulatorio, y lograr un enfoque más balanceado en el análisis costo-beneficio. Mientras tanto, los activistas e intelectuales conservadores dieron forma a sus argumentos, mientras esperaban que un líder que simpatizara con la agenda desregulatoria ocupara la Casa Blanca.

\subsection{Administración de George W. Bush}

Si bien el Presidente Bush no tenía un mandato electoral en pos de una agenda desregulatoria, su administración no fue particularmente favorable a la protección del medioambiente y durante su presidencia mantuvo una relación especialmente conflictiva con los grupos ambientalistas.

${ }^{29}$ Otra importante figura en este período fue Cass Sunstein, quien si bien es considerado como progresista, ha adoptado el análisis costo-beneficio y muchas de las sugerencias metodológicas que han provenido de comentaristas antirregulatorios. 
En lo que se refiere a la revisión centralizada y al análisis costobeneficio, el Presidente Bush eligió mantener vigentes durante los seis primeros años de su presidencia los decretos dictados por Clinton. Y cuando en 2007 dictó su propio decreto, no eliminó las disposiciones sobre la transparencia del proceso, la consideración de los impactos distributivos y la prevención de retrasos innecesarios. Los grupos ambientales estuvieron menos complacidos con sus designaciones para el staff de la OIRA, las cuales intensificaron el sentimiento, reinante entre los ambientalistas, de que el análisis costo-beneficio era antirregulatorio por naturaleza.

El primer presidente de la OIRA bajo la administración Bush fue John Graham, uno de los académicos que cultivaron la agenda antirregulatoria durante la presidencia de Clinton.

Los grupos ambientalistas y otros grupos pro regulación mantuvieron una relación antagónica con la OIRA mientras Graham estuvo a su cargo. Si bien los ambientalistas se sentían frustrados por la falta de voluntad del organismo para modificar las regulaciones basándose en sus comentarios, lograron algunas victorias. Apoyados por personas de la tercera edad y grupos como la Asociación Americana de Personas Retiradas (AARP), llevaron a cabo una enorme campaña para desacreditar "the senior death discount", una técnica que reducía el cálculo de los beneficios de las regulaciones cuando sus beneficiarios eran ancia$\operatorname{nos}^{30}$. El haber logrado este cambio en la metodología fue una gran victoria para los grupos pro regulación, y demostró su potencial para modificar el procedimiento cuando se involucran activamente en el debate metodológico.

Durante la presidencia de Graham, la OIRA fortaleció sus reglas de transparencia y cumplió consistentemente con los plazos para entregar sus conclusiones. De hecho, el análisis costo-beneficio supervisado por la OIRA logró convencer a la administración de adoptar importantes regulaciones ambientales. Sin embargo, los grupos pro regulatorios permanecían profundamente convencidos de que la administración Bush era hostil a sus intereses.

Probablemente la decisión más importante de la administración Bush respecto a la revisión centralizada y al análisis costo-beneficio fue la revisión del decreto 12,866. En su nueva versión, el decreto centrali-

${ }^{30}$ Véase el artículo escrito por Cindy Skrycki, "Under Fire, EPA Drops the 'Senior Death Discount'”, publicado en el Washington Post, el 13 de mayo de 2003. 
zó aun más el control sobre las agencias administrativas, expandió el rol de la revisión centralizada y estableció la obligación de detectar una falla de mercado antes de avanzar con la regulación propuesta ${ }^{31}$. Además, puso a representantes políticos a cargo de la revisión de las políticas regulatorias de todas las agencias, aumentando aun más el control presidencial sobre la burocracia, y posiblemente reduciendo el rol de los funcionarios de carrera.

En resumen, bajo la presidencia de George W. Bush el vínculo entre la agenda desregulatoria y el análisis costo beneficio se volvió casi completo.

Ahora bien, si el rechazo del análisis costo-beneficio por parte de los intereses progresistas y la adopción de la técnica por los grupos conservadores fueran un asunto de compromiso ideológico, tendríamos que esperar que estos grupos se mantengan en su posición, sin importar cuál sea el tema de fondo. Sin embargo, ello no ocurre en la práctica.

Cuando el gobierno federal buscó establecer regulaciones antiterrorismo, los grupos progresistas se opusieron, y el análisis costobeneficio fue la única herramienta que les permitió argumentar en contra de esas regulaciones. Al mismo tiempo, los grupos conservadores, que generalmente favorecían el análisis costo-beneficio, argumentaron en contra de éste, sosteniendo que era una "pérdida de tiempo y recursos”32. Esto parecería indicar que las posiciones actuales son el resultado de peleas políticas específicas en lugar de responder a una visión particular del mundo y que es posible, entonces, cambiarlas. Pero ni los grupos progresistas ni los conservadores deberían ser criticados por su flexibilidad. El apoyo ciego al análisis costo-beneficio no es una posición razonable para los grupos de interés con una agenda específica. De la misma forma, los grupos pro regulación son ingenuos en creer que sirven a sus profundos compromisos con el medio ambiente rechazando el análisis costo-beneficio por la forma en que la técnica ha sido aplicada. El análisis costo-beneficio no debería ser visto como malo en principio, sino malo o bueno dependiendo de cómo se lo use.

\footnotetext{
${ }^{31}$ Sobre este punto, Robert Pear escribió el artículo "Bush Directive Increases Sway on Regulation" en el $N$. Y. Times, de fecha 30 de enero de 2007, en A1.

${ }^{32}$ Véase Edmund L. Andrews: "Liberty and Security: New Scale for Toting Up Lost Freedom vs. Security Would Measure in Dollars”, aparecido en N. Y. Times del 11 de marzo de 2003 en A13 (citando a Charles Pena del Cato Institute).
} 
Es interesante advertir que las posturas adoptadas por progresistas y conservadores durante la guerra contra el terrorismo respondieron a la percepción de que el análisis costo-beneficio está inherentemente sesgado contra la acción del gobierno. Sin embargo, el análisis costo-beneficio es sólo inherentemente antirregulatorio en tanto los grupos pro regulación se mantengan pasivos como consecuencia de esa creencia.

Es importante que los grupos pro regulación se deshagan de ese letargo. Actualmente, su posición está afectando sus objetivos más de lo que los está ayudando. Es necesario que reconozcan que el análisis costo-beneficio, con las correcciones necesarias, puede transformarse en un estímulo para la acción. Cuando lleguen a esta conclusión, el análisis costo-beneficio va a dejar de ser inherentemente antirregulatorio, para transformarse en una herramienta cuyas ventajas dependerán de cómo sea utilizado.

\section{Falacias del actual análisis costo-beneficio}

\subsection{Consideraciones preliminares}

Existen algunos aspectos que podrían ser corregidos respecto al análisis costo-beneficio. Para ello debemos centrarnos en algunas de las falacias del actual análisis costo-beneficio. Sin embargo, previo a ello, es conveniente detenerse en la evaluación de los beneficios de una regulación, que en materia ambiental consisten generalmente en la preservación de la vida humana y del medio ambiente.

Aunque los intereses pro regulatorios fuera del gobierno han abandonado mayoritariamente la tarea de definir el análisis costo-beneficio, algunos actores dentro del gobierno han dado pasos para remover los prejuicios antirregulatorios del análisis costo-beneficio. Estos esfuerzos han culminado con las "Guías de la EPA sobre Costo-Beneficio", las cuales proveen a la Agencia Ambiental de los Estados Unidos (EPA, por sus siglas en inglés) con una fuente independiente de justificación para sus decisiones sobre costo-beneficio. Una de sus decisiones más importantes en esta materia fue el valor asignado a una vida humana, así como la definición de una metodología para determinar dicho valor.

Muchas de las regulaciones en materia ambiental salvan vidas. Para que podamos comparar los beneficios con los costos de una regulación, necesitamos trasladar el valor de las vidas salvadas a dólares. Para poder hacer esto, los economistas desarrollaron el concepto de "valor de una vida estadística". 
Cualquier método que busque cuantificar los beneficios de una regulación tiene que reconocer primero que las regulaciones primariamente reducen riesgos. Si un contaminante causa cáncer a una de cada cien mil personas expuestas, y dos millones y medio de personas están expuestas a esa sustancia, podemos esperar que veinticinco de ellas contraigan cáncer. Entonces, una regulación que prohíba ese contaminante tendrá un beneficio esperado de 25 vidas salvadas. Los economistas se dieron cuenta de que la pregunta apropiada era cuánto estaba dispuesta a pagar la gente para evitar estos pequeños riesgos, y ese monto podía ser aplicado a las poblaciones afectadas para valorar las vidas salvadas por la regulación.

Existen dos técnicas aceptadas para medir cuánto está dispuesta una persona a pagar para evitar pequeños riesgos. La técnica de "preferencias indicadas”, también llamada de "valoración contingente”, les pregunta a las personas cuánto están dispuestas a pagar para evitar un riesgo particular. Las preguntas en la encuesta pueden tener diversas formas. Por ejemplo, algunas encuestas miden el efecto de la contaminación del agua en los valores que las personas asignan a las propiedades $^{33}$, y otras les preguntan a los entrevistados cuánto están dispuestos a pagar por determinadas características que reducen los riesgos en productos que habitualmente consumen ${ }^{34}$.

Por otra parte, la técnica de "preferencias reveladas" trabaja en base a decisiones que las personas ya tomaron, apoyándose generalmente en estudios del mercado de trabajo. Este método tiene la ventaja de estar basado en transacciones de mercado reales, en lugar de basarse en respuestas a una pregunta hipotética. Típicamente, los estudios de preferencias reveladas se basan en el análisis estadístico de los sueldos y miden la compensación adicional que se les paga a los trabajadores por aceptar un trabajo de mayor riesgo cuando otras características del trabajo — como la educación necesaria, habilidades, condiciones laborales y prestigio- permanecen constantes.

En relación con el concepto de "vida estadística" cabe señalar que es una expresión que puede resultar un poco confusa. El valor de una vida estadística es un número agregado. Si una persona promedio

${ }^{33}$ Simons y Winson-Geideman (2005).

34 Véase Johannesson et al. (1996), quienes comparan la disposición a pagar por elementos de seguridad en automóviles versus un programa de seguridad que considera el mejoramiento en la calidad de caminos. 
recibe ochocientos pesos extras como compensación por verse expuesta a un riesgo de uno en diez mil de morir, decimos que el valor de una vida estadística es ochocientos por diez mil, es decir ocho millones. Éste no es el valor de una vida humana en particular. Tampoco es el valor que esperaríamos que una persona pague para evitar un ciento por ciento la probabilidad de morir. Este número varía de una persona a otra y muy probablemente sea cercano al valor de todos sus activos y de cualquier activo que estuviera dispuesta a pedir prestado o a robar. En cambio, el valor de una vida estadística representa la suma de los montos que las personas están dispuestas a pagar para evitar riesgos muy pequeños. El valor de una vida estadística podría ser más precisamente llamado "diez mil veces el valor de eliminar un riesgo de uno en diez mil de morir".

Por otra parte, cabe tener en cuenta algunos aspectos de relevancia respecto a la asignación de un valor monetario a la preservación del medio ambiente. Los recursos naturales tienen muchos usos. Son la materia prima con la que fabricamos otros bienes, pero también los usamos para la disposición final de nuestros residuos y para nuestras necesidades más básicas como respirar o tomar agua. La recreación y el entretenimiento son también usos comunes de los recursos naturales. Muchos de nosotros alguna vez nadamos en un lago u océano, visitamos algún parque nacional para admirar ríos y montañas, acampamos, esquiamos, cazamos, en fin, usamos la naturaleza con fines de recreación y entretenimiento. En cualquiera de estos casos, los recursos naturales tienen un claro valor económico.

Pero además de este valor de uso, muchas personas le asignan a la protección del medio ambiente un valor no relacionado con el uso, al que podemos llamar "valor de no uso". El valor de no-uso puede dividirse en tres categorías ${ }^{35}$. La primera es el "valor de opción”, es decir, el valor que las personas le asignan a la posibilidad de usar un recurso en algún momento en el futuro. Por ejemplo, aunque una persona no tenga planes inmediatos de visitar un parque nacional, puede preferir que en ese parque no se lleven a cabo actividades mineras para que no desaparezca la posibilidad de visitarlo en el futuro. Entonces, un recurso natural puede tener valor para una persona aun si ésta no lo usa actualmente ni planea usarlo, porque su existencia le garantiza la opción de usarlo en algún momento en el futuro.

${ }^{35} \mathrm{Al}$ respecto, véase a Cross (1989). 
Una forma relacionada de valor de no-uso es el "valor como legado". Una persona puede no asignarle ningún valor de opción al uso de un recurso natural, pero puede querer preservarlo para las generaciones futuras. En estos casos decimos que el recurso tiene un valor como legado.

El último tipo de "valor de no-uso" es el "valor de existencia". Los recursos naturales tienen valor de existencia, no por la posibilidad de usarlos en el futuro, o de legarlos a otros, sino simplemente por existir. Por ejemplo, una especie en peligro de extinción, que a nadie le importa ver y que no tiene ningún valor de uso, puede tener un valor de existencia si las personas prefieren que la especie exista a que se extinga. Del mismo modo, muchas personas están dispuestas a pagar para preservar áreas de la selva tropical aun cuando ni ellas ni sus herederos deseen visitarla. El hecho de que la gente esté dispuesta a hacer sacrificios económicos para preservar recursos naturales que no tienen un uso posible demuestra que hay un valor de existencia que motiva su comportamiento.

El problema con el valor de existencia es que, como no hay un mercado, se nos hace difícil observar el precio que las personas están dispuestas a pagar por una unidad adicional de valor de existencia. Y sin ese precio no sabemos qué valor darles a las regulaciones que preservan la existencia de los recursos naturales.

Para solucionar este problema, los economistas han recurrido a los estudios de preferencias indicadas. Como vimos, en los estudios de preferencias indicadas se les pregunta a las personas por sus valoraciones de los recursos naturales. En 1989 hubo un derrame de petróleo en las costas de Alaska que afectó significativamente al ecosistema. En el contexto de la demanda iniciada por el estado de Alaska contra Exxon, la empresa propietaria del barco que ocasionó el derrame, se llevó a cabo un estudio de preferencias indicadas para determinar cuál era el valor que los estadounidenses le daban a mantener el área libre de derrames de petróleo. Como parte del estudio se entrevistó a mil individuos seleccionados al azar del total de la población de los Estados Unidos. Durante las entrevistas se les mostraban a los participantes fotografías del área y se les daba una descripción del derrame, sus consecuencias y cómo se llevaba a cabo la limpieza de la zona. Después los entrevistados tenían la opción de votar por distintos progra- 
mas para proteger el área de futuros derrames de petróleo. El costo de estos programas estaba expresado como un impuesto que cada propietario pagaba sólo una vez. El valor de este impuesto variaba entre diez y doscientos cincuenta dólares, dependiendo del nivel de protección deseado. Y en base al análisis de los votos se estimó un valor de existencia de dos mil ochocientos millones de dólares ${ }^{36}$.

Una vez analizada la forma de valorar los beneficios de una regulación, es posible concentrarse en las falacias del análisis costobeneficio. Estas falacias están afianzadas en su metodología porque, como vimos, quienes estuvieron a cargo de su desarrollo durante las últimas décadas estaban fuertemente sesgados contra la regulación.

\subsection{Primera falacia: "Todas las consecuencias colaterales de una} regulación son malas"

Durante las últimas décadas, el análisis costo-beneficio se volvió más sofisticado y comenzó a tener en cuenta las consecuencias colaterales de la regulación. A la consideración de estas consecuencias se denomina "análisis de compensación de riesgos" (risk trade-off analysis). La idea es simple. Cuando tratamos de minimizar ciertos riesgos, las medidas que adoptamos pueden exacerbar otros riesgos. Entonces, para lograr un análisis completo del impacto de la regulación, debemos tener en cuenta no sólo cómo reduce el riesgo al que se dirige sino también la generación de riesgos colaterales.

Los grupos conservadores han usado con éxito esta metodología para convencer a los tribunales de dejar sin efecto ciertas regulaciones ambientales. Por ejemplo, un tribunal sostuvo que la EPA tenía que analizar cuidadosamente los efectos colaterales negativos de su propuesta para disminuir los niveles de ozono troposférico, entre los que se incluía el aumento de los casos de cáncer de piel.

Podríamos decir que el "análisis de compensación de riesgos" es una herramienta útil. Si una regulación particular salva a una especie en peligro de extinción pero tiene como efecto colateral la extinción de otra, sin duda tendríamos que contemplar ese costo colateral en el análisis costo-beneficio. El problema es que los defensores del actual

${ }^{36}$ Véase Carson et al. (2003). 
análisis costo-beneficio tienden a fijarse sólo en las consecuencias colaterales negativas. Pero no hay razón para creer que los beneficios complementarios son menos comunes que las consecuencias colaterales. La aspirina, por ejemplo, además de su acción analgésica, tiene el beneficio complementario de prevenir los ataques $\operatorname{cardíacos}^{37}$. De hecho, probablemente este beneficio sea mayor que el fin para la cual fue creada en primer lugar.

Para mostrar cómo se pueden pasar por alto los beneficios complementarios de una regulación vamos a discutir las tres clases principales de riesgos colaterales: la compensación directa de riesgos, el efecto sustitución y el efecto adormecedor ${ }^{38}$.

La compensación directa de riesgos es la categoría más clara. En estos casos, la regulación de un riesgo genera otro riesgo. Por ejemplo, si reducimos el cloro que le ponemos al agua, disminuimos el riesgo de cáncer pero aumentamos el riesgo de contraer enfermedades microbianas ${ }^{39}$. Otro ejemplo es el nitrito de sodio, que al mismo tiempo es una sustancia cancerígena y otorga una protección importante contra el botulismo ${ }^{40}$.

Sin embargo, no hay razón para creer que los beneficios secundarios son menos comunes que los riesgos colaterales. Por ejemplo, para cumplir con la regulación ambiental del agua en los Estados Unidos, las municipalidades construyeron humedales como una alternativa a las plantas de tratamiento de agua $^{41}$. Estos humedales generaron muchos beneficios secundarios: crearon hábitats para muchas especies, sirvieron para secuestrar dióxido de carbono, para controlar la erosión de las zonas costeras, y crearon oportunidades recreativas y de investigación para mucha gente ${ }^{42}$. Del mismo modo, según el Protocolo de Kyoto, los países pueden usar sumideros de carbón para cumplir con sus obligaciones de reducir las emisiones de gases del efecto

${ }^{37}$ American Heart Association (Asociación Estadounidense del Corazón): “La Aspirina en la Prevención de Derrames Cerebrales y Ataques Cardíacos”. http:// www.americanheart.org/presenter.jhtml?identi?er=4456.

${ }^{38}$ Sunstein (1996).

39 Véase Graham y Wiener (1995), citando a Christopher Anderson (1991): “Cholera Epidemic Traced to Risk Miscalculation”, en revista Nature Vol. 354, pp. 255.

${ }^{40}$ Véase Lave (1981).

41 Sobre este punto, véase el informe de la Oficina de Aguas de la EPA: “Constructed Wetlands for Wastewater Treatment and Wildlife Habitat”, disponible en http://www.epa.gov/owow/wetlands/construc/.

42 Piper y Platt (1998). 
invernadero. Pero estos sumideros de carbono tienen como beneficio secundario la conservación de los bosques en países en vías de desarrollo, y de esa forma mantienen los hábitats de una gran cantidad de especies y ayudan a conservar la biodiversidad ${ }^{43}$.

Otro ejemplo son las regulaciones que limitan las emisiones de monóxido de carbono de los automóviles y otros vehículos, y que tienen el beneficio secundario de reducir las muertes por envenenamiento con monóxido de carbono y los suicidios ${ }^{44}$. De hecho, un estudio encontró que la regulación del monóxido de carbono en los Estados Unidos tuvo el beneficio "no anticipado" de salvar en promedio veinticinco mil vidas por año; mientras que la EPA sólo había considerado los beneficios ambientales de la regulación, que eran de entre 212 y 551 vidas salvadas. En este caso, los beneficios secundarios sobrepasaron por mucho a los beneficios directos de la regulación.

El efecto sustitución ocurre cuando una regulación hace que la gente cambie un producto o proceso por otro que tiene sus propios riesgos. Por ejemplo, cuando se prohibió el ciclamato, que es un tipo de edulcorante artificial, porque se descubrió que era cancerígeno, muchos consumidores empezaron a usar sacarina, que también se ha demostrado que puede ocasionar cáncer ${ }^{45}$. Otro ejemplo son las regulaciones que tratan de hacer que la energía nuclear sea lo más segura posible, y que como sus costos son muy altos pueden tener el efecto secundario de fomentar el uso de otros métodos de energía que a su vez tienen riesgos propios — por ejemplo, contribuir al cambio climático. Pero este efecto también se da del lado de los beneficios. Por ejemplo, algunos estudios demostraron que las reducciones en las emisiones de gases del efecto invernadero tienen el efecto positivo de generar reducciones en otros contaminantes ${ }^{46}$. Para reducir las emisiones de dióxido de carbono, los productores de electricidad usan menos combustibles o eligen combustibles más limpios. Estas sustituciones, que originalmente están pensadas para disminuir las emisiones de gases del efecto invernadero, también reducen las emisiones de otros contaminantes como el ozono, los óxidos de nitrógeno y el dióxido de

\footnotetext{
${ }^{43}$ Kaiser (2000).

${ }^{44}$ Shelef (1994).

${ }^{45}$ Graham y Wiener (1995).

${ }^{46} \mathrm{Al}$ respecto, véase Burtraw et al. (2001).
} 
azufre. De hecho, distintos estudios encontraron una gran variedad de beneficios secundarios asociados con las reducciones de dióxido de carbono $^{47}$, que fueron estimados entre 13 y 14 dólares por cada tonelada de dióxido de carbono no emitida ${ }^{48}$.

Por último, el efecto "adormecedor" se da cuando ciertas regulaciones "adormecen" a los consumidores, haciéndoles prestar menos atención a los riesgos. Bajo esta teoría, el establecimiento de medidas de seguridad puede llevar a que los consumidores sobrestimen la seguridad del producto y tengan menos cuidado cuando lo usan ${ }^{49}$. El ejemplo típico de este efecto son las tapas a prueba de niños utilizadas en Estados Unidos para evitar que ellos tomen medicamentos por accidente y se intoxiquen. Un estudio probó que a pesar de la regulación, los casos de intoxicación no se redujeron y, aparentemente, esto se debió a un aumento de la "irresponsabilidad de los padres" que dejaron de prestarle atención al problema y se olvidaron de cerrar los frascos.

Como contrapartida al efecto "adormecedor" podría existir un efecto “concentración” por el cual la adopción de medidas para proteger la salud hace que las personas tomen conciencia de la necesidad de adoptar medidas de seguridad, más allá de las que expresamente están cubiertas por la regulación. Por ejemplo, la atención de las personas hacia el cambio climático puede contribuir a que tomen conciencia sobre el uso de los recursos no renovables, aun cuando estos recursos no tengan una relación directa con el cambio climático. O el uso de una etiqueta especial para los productos “orgánicos” puede ayudar a que la gente se preocupe más por cuán saludable es la comida que elige, fijándose en el contenido de grasa o de azúcar ${ }^{50}$.

${ }^{47}$ Véase Burtraw y Toman (1998), quienes estiman un rango entre US \$2,88 a US \$78,85 por tonelada reducida de carbón.

${ }^{48}$ Burtraw et al. (2001).

${ }^{49}$ Ver Viscusi (1992).

${ }^{50}$ Podría argumentarse que el efecto de atención que hemos descrito pueda, en efecto, cambiar las preferencias de las personas. No necesitamos efectuar esa distinción aquí; basta con demostrar que el efecto adormecedor puede ser contrarrestado o complementado por un efecto que apunte en la dirección contraria. El impacto de la regulación en las preferencias es un tema complejo para el análisis costo-beneficio, toda vez que no es claro si preferencias ex ante o ex post se deben tomar en cuenta al juzgar regulaciones. Éste es el centro de la distinción entre disposición-a-pagar y disposición-a-aceptar. Si bien estos problemas son interesantes desde el punto de vista teórico, y pueden de hecho presentar problemas prácticos en algunos casos, superan el alcance de este trabajo. 
Dado que el análisis de compensación de riesgos dirige a los reguladores a investigar sólo los riesgos colaterales y no los beneficios complementarios, éste se encuentra sistemáticamente sesgado contra la regulación. La solución es simple. Las agencias regulatorias deberían considerar los efectos secundarios positivos de la regulación, en lugar de centrarse sólo en los negativos. Esta recomendación no es utópica: si la cadena causal entre el beneficio y la regulación es demasiado atenuada, los reguladores no necesitan gastar recursos rastreando todos los efectos positivos. Sin embargo, debería existir paridad entre los beneficios complementarios y los riesgos colaterales. En la medida en que un beneficio complementario o un riesgo colateral es estudiado, el otro también debería serlo.

\subsection{Segunda falacia: "La gente mayor es menos valiosa"}

La segunda falacia del análisis costo-beneficio consiste en afirmar que la gente mayor es menos valiosa. Como vimos anteriormente, la forma estándar de medir el beneficio de una regulación que salva vidas es fijarnos en cuánto están dispuestas a pagar las personas por evitar un determinado riesgo, y en base a eso establecer el valor de una vida estadística.

En los últimos años se intentó sustituir este método por el de "el valor de los años de vida”. Este método genera la segunda falacia que es relevante analizar: "la vida de los ancianos vale menos que la de las personas jóvenes, como consecuencia de sus menores expectativas de vida”. La idea es la siguiente: como las personas jóvenes van a perder en promedio más años de vida si mueren, sus vidas tienen un valor mucho mayor. De hecho, como resultado de aplicar este método de valoración, la vida de una persona de 40 años tiene un valor siete veces mayor que la de una persona de 70 años. Pero, como vamos a ver, este resultado es inconsistente con la teoría económica y con los datos empíricos sobre cómo las personas valoran el riesgo.

A diferencia del individuo promedio de los estudios salario-riesgo —que en general tiene 40 años y una esperanza de vida de $35^{51}$-, el beneficiario de una regulación puede tener 70 años y muy mala salud, y tal vez su expectativa de vida sea de alrededor de 5 años. Quienes

${ }^{51}$ Véase Arrow (1950). 
proponen el uso del método del "valor de los años de vida" sostienen que es inapropiado aplicar el valor de una vida estadística que se deriva de estudios de trabajadores de 40 años a individuos más viejos, a los que les quedan muchos años de vida menos.

Entonces, proponen usar un valor constante por cada año de vida. Y para calcular el valor de un año de vida toman el valor de una vida estadística y la dividen por la expectativa de vida promedio de los individuos que participaron del estudio de salario-riesgo.

Pero el resultado de usar el mismo valor para todos los años de vida es que las vidas de los ancianos y las personas poco saludables tienen un valor muchísimo menor. Por ejemplo, supongamos que un año de vida vale ciento ochenta mil dólares, la vida de un anciano con una expectativa de vida de cinco años valdría novecientos mil dólares; es decir, sólo un séptimo de los seis millones trescientos mil dólares que vale la vida de un individuo promedio.

Un ejemplo de las consecuencias de utilizar esta metodología se aprecia con el esmog. El ozono a nivel del suelo, que es a lo que llamamos esmog, puede causar asma, daño permanente en los pulmones y hasta la muerte de las personas expuestas. En Estados Unidos, la EPA es la encargada de establecer los niveles permisibles de ozono.

Pero regular el ozono no es tarea fácil. El ozono a nivel del suelo generalmente se genera por una reacción química en la que compuestos orgánicos volátiles y óxidos de nitrógeno se mezclan en presencia de la luz solar. Estos compuestos tienen miles de orígenes, incluyendo los tubos de escape de los autos y los vapores de gasolina. El problema es que controlar la contaminación asociada con los autos es muy difícil, básicamente porque aun cuando logremos disminuir el nivel de contaminación por kilómetro manejado, la cantidad de kilómetros manejados aumenta cada día ${ }^{52}$. $\mathrm{Y}$ a esto tenemos que sumarle que las soluciones de ingeniería disponibles son escasas y costosas ${ }^{53}$.

${ }^{52}$ EPA ha creado una representación gráfica de estas tendencias. “Cars Are Getting Cleaner, But People Are Driving More”. U.S. EPA, Oficina de Fuentes Móviles, Automóviles y Ozono, EPA400-F-92-006 (Hoja de Datos OMS-4, enero. 1993). Disponible en http:/ /www.epa.gov/otaq/consumer/04-ozone.pdf.

${ }^{53}$ Conforme a la propia EPA, las estimaciones de cumplimiento del estándar de calidad del aire para ozono de 1997 fue de 48 miles de millones de dólares al año (billions, en inglés norteamericano: 48,000,000,000) (Lutter, 1999). Otras estimaciones son significativamente más altas. Por ejemplo, Randall Lutter, del Centro Conjunto de la AEI y 
Entonces, si la EPA decidiera establecer una regulación más estricta, esto significaría un enorme dolor de cabeza para las industrias afectadas. ¿Qué argumento usarían las industrias para quejarse de todos los problemas que les genera salvar más vidas? Una posible respuesta es que el beneficio de ese dolor de cabeza es menor de lo que parece, porque "salvar vidas" no debería ser entendido como salvar vidas individuales sino como salvar años de vida. Y como los mayores beneficiarios de esta regulación son las personas con problemas respiratorios, que generalmente tienen una expectativa de vida menor que la del trabajador estadounidense promedio, los beneficios de la regulación van a ser considerablemente menores y tal vez no logren igualar a los costos.

De hecho, si la exposición a elevados niveles de ozono resulta en la muerte de individuos con una expectativa de vida promedio de cinco años, el beneficio de la regulación, calculado con el método de los años de vida, sería un séptimo del beneficio calculado con el valor de una vida estadística. Y así, un beneficio de quinientos mil millones de dólares se transforma rápidamente en uno de setenta millones, es decir, se reduce en un $85 \%$.

Pero más allá de estas consecuencias, la metodología del "valor de los años de vida” no surge de la teoría económica ni encuentra apoyo en los hechos.

Este enfoque es fundamentalmente inconsistente con principios importantes de la teoría económica en donde, como vimos, el valor es determinado en base a la disposición a pagar ${ }^{54}$. Y entonces, para que la disminución del valor asignado a una reducción de mortalidad por la edad del beneficiario tenga sustento económico, tendríamos que probar que la disposición a pagar por la reducción del riesgo disminuye cuando una persona envejece. Es decir, que cuanto más envejecemos, menos estamos dispuestos a pagar por regulaciones que disminuyan el riesgo de morir.

Brookings, estimó que el cumplimiento del estándar de 1997 para ozono es inviable, pues tendría costos de cumplimiento de un billón de dólares al año (en inglés norteamericano trillion: 1,000,000,000,000). En el caso de otras siete grandes ciudades, el cumplimiento sería potencialmente prohibitivo, para las cuales su costo en el 2010 sería aproximadamente de 70 miles de millones de dólares al año (en inglés norteamericano, billions).

${ }^{54}$ Véase Field y Field (1997), quienes señalan que "la idea fundamental del valor se encuentra relacionada con la disposición a pagar; el valor que pueda tener un bien para alguien es lo que esa persona está dispuesta a pagar por él”. 
Pero en lugar de usar la disposición a pagar de los individuos como una aproximación al valor de la reducción del riesgo, el método del valor de los años de vida simplemente asume una relación lineal descendente entre la edad de la persona y el valor de su vida.

Esta presunción es inconsistente con la observación económica estándar de que los individuos generalmente asignan un mayor valor a los bienes cuando hay una oferta limitada de ellos. Cuando las personas van envejeciendo, pueden anticipar que les quedan menos años de vida en el futuro. Dada esta escasez, la teoría económica nos diría que los ancianos valorarán más sus años de vida futuros que una persona joven. Sin embargo, esta técnica adopta un valor por año de vida constante, y por tanto todos los años de vida son valorados de la misma manera. Al asumir que no existe diferencia entre el valor que una persona de cuarenta años y una persona de setenta le asignan a un año adicional de vida, el método del "valor de los años de vida" pasa por alto el efecto de la escasez ${ }^{55}$.

Y como consecuencia de todo esto, este método hace que los esfuerzos regulatorios se concentren en reducir los riesgos que afectan a los más jóvenes, otorgándoles beneficios regulatorios a aquellos que los valoran menos, lo que va en contra de la lógica económica estándar. Generalmente, el sistema más eficiente es el que otorga los recursos a las personas que los valoran más. Y el método de los años de vida hace exactamente lo opuesto.

Además, mientras las personas envejecen, tienen mayores ingresos y riqueza. Y como la disposición a pagar para evitar riesgos aumenta cuando aumenta el ingreso, tendríamos que esperar que la disposición a pagar sea mayor cuando las personas envejecen, contrariamente a lo que predice el método de los años de vida.

De hecho, varios modelos - todos los cuales han sido ignorados por quienes proponen esta metodología - han tratado de determinar cómo cambia la valoración de riesgo de las personas con la edad. Y si bien todavía no hay una respuesta clara, ninguno de estos estudios apoya la relación lineal decreciente entre la expectativa de vida y la

55 Una posible solución a esto podría consistir en aumentar la valoración de los años-vida a medida que el número de los años esperados en la vida de una persona disminuye. Una versión de esta solución ha sido propuesta por John Graham. Véase "Memorandum from John Graham, Administrator, OIRA, to the President's Management Council” (mayo 30, 2003), disponible en http://www.whitehouse.gov/omb/inforeg/pmc_benefit_cost_memo.pdf. 
disposición a pagar que postula el método de la "valoración de los años de vida”. Entonces, es claro que no hay una justificación teórica para el uso de este método.

Por otra parte, los estudios empíricos sobre la relación entre la edad y la disposición a pagar muestran que el método de los años de vida carece de justificación empírica y que lleva a una sistemática subestimación de los beneficios regulatorios de los programas dirigidos a los ancianos. De hecho, aun los estudios que muestran una relación entre edad y disposición a pagar no apoyan un declive tan pronunciado y constante como asume el método de "los años de vida."

Entonces, podemos decir que el uso de esta técnica divorcia al análisis costo-beneficio de sus fundamentos económicos. El análisis costo-beneficio nos sirve para identificar la regulación que es económicamente eficiente, y por lo tanto todas sus metodologías tienen que ser coherentes con la teoría económica. Es claro que la metodología de la valoración de los años de vida no logra esta coherencia. Y entonces su uso equivale a meter de contrabando conclusiones no económicas en el análisis costo-beneficio, que lo único que indican es cómo las personas “deberían” valorar los riesgos, pero no nos dicen nada sobre cómo las personas los valoran en el mundo real. Y esto pervierte el significado de la técnica y a la larga va a terminar dándonos conclusiones confusas e inútiles.

Resumidamente, el uso del método de los años de vida da como resultado la falacia de que las personas ancianas son menos valiosas que las jóvenes, y por lo tanto debería ser abandonado. El estado actual de la ciencia es que la vida humana debe valorarse en base al valor de una vida estadística, calculada en base a estudios de preferencias reveladas. Pero aun si pudiera demostrarse que la edad tiene efectos consistentes en la disposición a pagar para evitar riesgos, todavía nos quedarían muchos temas difíciles para resolver, entre ellos la injusticia fundamental que implica tratar a las vidas de forma diferente, y cómo valorar la vida de los niños (quienes, como no tienen bienes, tienen una disposición a pagar muy pequeña). Hasta hoy hemos evitado todos estos problemas usando un valor promedio. Entonces, antes de abandonar esta estrategia, quienes proponen nuevas metodologías tienen que demostrar que pueden resolver estos problemas, al menos de forma igual de satisfactoria que el método actual. 
5.4. Tercera falacia: "La gente siempre prefiere postergar las cosas malas"

\subsubsection{Elementos principales del descuento}

El descuento es una técnica que reduce el valor de los dólares futuros para traducirlos en dólares a valor presente. El uso de esta técnica se basa en la idea de que la gente prefiere la gratificación inmediata, lo que hace que un dólar hoy valga más que un dólar el año que viene. Algunas veces los beneficios ambientales y de salud de una regulación ocurrirán en el futuro.

Por ejemplo, si un contaminante tiene un período de latencia prolongado, pueden pasar décadas entre la exposición al contaminante y la manifestación de los síntomas de la enfermedad. En estos casos, los beneficios de adoptar una regulación que reduzca ese riesgo son descontados a valores presentes para que sea posible compararlos con los costos estimados de la regulación. Es decir, usamos el descuento como una herramienta para reflejar el hecho de que las personas preferirían pagar significativamente más para eliminar un riesgo inmediato que para eliminar un daño que ocurrirá en el futuro.

Un ejemplo de cómo se utiliza la técnica del descuento respecto a contaminantes con largos períodos de latencia es el caso de la regulación del asbesto.

El asbesto es un mineral que durante siglos fue usado por sus propiedades de resistencia al fuego. La exposición al asbesto puede reducir la función del pulmón, en casos extremos llevar a alteraciones respiratoria (asbestosis), y hasta generar un tipo de cáncer muy poco común (mesotelioma).

En cualquier caso, existe un considerable retraso entre el momento de la exposición y la manifestación de los primeros síntomas de estas enfermedades: de 10 a 20 años para el caso de la asbestosis, y de 35 a 45 años para el mesotelioma. Cuando la EPA consideró la posibilidad de prohibir el uso del asbesto, el problema de cómo valorar los beneficios de la regulación que ocurrirían a muy largo plazo fue central. Cuando la agencia presentó un borrador de la regulación al OMB, este organismo lo objetó bajo el argumento de que los beneficios obtenidos no superaban a los $\operatorname{costos}^{56}$. El análisis costo-beneficio del OMB

${ }^{56}$ Véase la carta de Robert P. Bedell, subadministrador de la Oficina de Información y Asuntos Regulatorios, a A. James Barnes, subadministrador subrogante de la EPA (mar. 27, 1985), reimpresa en Menell y Stewart (1994). 
usó un valor por cada caso de cáncer evitado de un millón de dólares y lo descontó a una taza del $4 \%$ por cada año del período de latencia ${ }^{57}$. El efecto de descontar ese valor por los 40 años del período de latencia fue una reducción del valor de cada vida a \$208.000.

\subsubsection{Ajustes necesarios al descuento}

El descuento puede ser una técnica apropiada para reflejar las preferencias de las personas por obtener beneficios inmediatos en lugar de beneficios futuros. Sin embargo, esta idea necesita una pequeña corrección: si bien las personas generalmente prefieren recibir beneficios antes en lugar de después, éstas no siempre optan por ello. Debemos tener en cuenta que, a veces, cuando las personas son afectadas por el miedo, prefieren que las cosas malas pasen lo más rápido posible $^{58}$. Este factor también cumple un papel en las enfermedades con largos períodos de latencia: el bienestar de las personas probablemente se reduzca significativamente durante todo el período de latencia por el miedo a la enfermedad y al sufrimiento que ella implica. De hecho, algunos estudios demuestran que la gente está dispuesta a pagar el doble para evitar morir de cáncer que para evitar una muerte instantánea ${ }^{59}$.

Entonces necesitamos aumentar el valor que les asignamos a las regulaciones que evitan o disminuyen estos riesgos para evitar ser presa de la falacia que sostiene que las personas siempre prefieren postergar las cosas malas. La práctica actual, que implica descontar los beneficios futuros a la taza de los instrumentos financieros estándares, muy probablemente esté subestimando el valor de evitar este tipo de enfermedades.

La decisión de utilizar o no el descuento en el contexto de enfermedades con largos períodos de latencia es una cuestión que depende de las preferencias temporales de las personas. Pero el uso de esta técnica en el contexto de las generaciones futuras es muy diferente. Cuando decidimos cuánto gastar hoy para reducir riesgos ambientales que afectarán a nuestros hijos y nietos, no estamos hablando de las

\footnotetext{
${ }^{57}$ Ibíd.

${ }^{58}$ Véase Berns et al. (2005).

${ }^{59}$ Sobre este punto, véase "State-of-the-Art Health Values" en Tolley et al. (1994).
} 
preferencias temporales de un grupo de personas, sino de asignación de recursos entre personas que viven en diferentes espacios temporales. Estas decisiones son de naturaleza moral, no empírica.

La práctica de descontar beneficios futuros está extendida entre las agencias regulatorias. Y de hecho una posible explicación de por qué la administración Bush no adoptó medidas significativas para controlar los gases del efecto invernadero radica en el uso de esta técnica: como los beneficios de mitigar el cambio climático ocurrirán en el futuro, y los costos se deben soportar en el presente, deberíamos descontar los beneficios futuros a su valor presente. Usando una tasa de descuento del 10 por ciento, la sociedad estará dispuesta a pagar U\$S 50,000 para salvar una vida en 50 años, y U\$S 435 para salvar una vida en 100 años.

Se puede intentar resolver este problema en un mundo simplificado. En este mundo hipotético existen dos personas con funciones de utilidad idénticas, ellas viven cincuenta años cada una en períodos subsecuentes pero no superpuestos: es decir, la persona "uno" vive entre los años 1 y 50 y la persona “dos” vive entre los años 51 y 100. En este mundo existen 100 unidades de recursos, y no es posible llevar a cabo ninguna actividad productiva. Consumir una unidad de recurso implica destruirla por completo. Darle la misma consideración a cada habitante implicaría una distribución igual de los recursos, de forma tal que cada persona reciba 50 unidades. Sin embargo, si usamos una tasa de descuento positiva, incluso una relativamente pequeña, la mayoría de los recursos le será otorgada al primer habitante. Es difícil sostener que dicha asignación es justa. De hecho, si los dos habitantes estuvieran localizados en islas separadas en un mismo espacio temporal, sería manifiestamente injusto darle más recursos a uno que a otro basándose en algún criterio arbitrario como cuál de los dos vive en una isla que está más al norte.

Entonces, pareciera que tenemos en claro que si la gente está separada en el espacio, pero habita el mismo marco temporal, la justicia requiere una distribución equitativa de los recursos disponibles. Nuestra intuición debería ser igualmente clara en el contexto intergeneracional, en donde la gente comparte el mismo espacio pero vive en un marco temporal diferente. Lo que está en juego es una decisión de distribución entre individuos, lo cual es inevitablemente una decisión moral que debería estar gobernada por nociones de justicia y equidad. 


\subsubsection{Alternativas al descuento}

Si no usamos el descuento para definir nuestras obligaciones morales hacia las generaciones futuras, necesitamos una alternativa. En este sentido, hay varias teorías que ofrecen mayor atractivo desde el punto de vista de nuestras intuiciones morales.

El concepto de desarrollo sustentable es un modelo influyente de responsabilidad intergeneracional ${ }^{60}$. El desarrollo sustentable ha sido definido como aquel que "satisface las necesidades del presente sin comprometer las posibilidades de las generaciones futuras de satisfacer sus propias necesidades" ${ }^{\prime \prime}$. Si bien hay muchas ideas diferentes sobre cuáles son las obligaciones de la generación presente ${ }^{62}$, también se han logrado algunos acuerdos. Nuestra obligación principal hacia las generaciones futuras generalmente se define en términos de restricciones que especifican cuánto tenemos que dejarles ${ }^{63}$. Y se permite algún nivel de destrucción de los recursos naturales, siempre que las generaciones futuras sean compensadas de alguna otra manera, por ejemplo median-

${ }^{60}$ Véase Meyers y Muller (1996).

${ }^{61}$ Reporte de 1987 de la Comisión Mundial sobre Medio Ambiente y Desarrollo (World Commission on Environment and Development), el cual ha sido generalmente citado como el Reporte Brundtland, por su director. Véase World Commission on Environment and Development (1987).

${ }^{62}$ Dos informes de gran influencia, uno basado en derecho internacional y el otro en economía, han sido elaborados por Edith Brown Weiss y Robert Solow, respectivamente. Brown Weiss da una interpretación de desarrollo sustentable basada en la tradición del derecho internacional, en la cual tres principios básicos constituyen el centro del desarrollo sustentable (Weiss, 1991). En primer lugar, el principio de conservación de opciones requiere que cada generación preserve las bases de los recursos naturales y culturales de manera que las opciones disponibles para futuras generaciones no sean excesivamente restringidas. En segundo lugar, el principio de conservación de calidad requiere que cada generación prevenga un deterioro de la calidad ambiental del planeta. Tercero, el principio de conservación de acceso requiere que cada generación provea a sus miembros con iguales derechos de acceso al legado de pasadas generaciones, así como para conservar este acceso para el beneficio de futuras generaciones. Véase Weiss (1988). En contraste, de acuerdo al economista Robert Solow, la sustentabilidad requiere que cada generación futura tenga los medios para contar con un bienestar equivalente al de sus predecesores (1993). Solow argumenta que cada generación debe utilizar sus recursos no renovables y ambientales en una forma que no restrinja la capacidad de futuras generaciones de tener un estándar de vida similar. Él admite que algunos recursos únicos e irreemplazables, como algunos parques nacionales, deben ser preservados por su propio bien, pero afirma que el consumo de recursos naturales que no sean únicos, así como de recursos ambientales debe ser permisible mientras sean reemplazados por otros recursos, tales como conocimientos tecnológicos.

${ }^{63}$ Es interesante comparar los planteamientos de Weiss (1991) con Solow (1993). 
te el progreso tecnológico. Sin embargo, se entiende que algunos recursos naturales, como los parques nacionales, son irreemplazables y en estos casos nuestra generación tiene la obligación de preservarlos.

Existen importantes críticas al concepto de desarrollo sustentable. Primero, el desarrollo sustentable es una obligación no específica: no establece claramente cómo lidiar con problemas tales como el crecimiento de la población, y tampoco establece si la generación presente tiene que dejar recursos suficientes para mantener los niveles actuales de mejoras en las condiciones de vida. Además, pareciera que el desarrollo sustentable impone muy pocas obligaciones a la generación presente. Por ejemplo, el criterio del desarrollo sustentable no requeriría que se haga ahora un gasto trivial que se traduzca en grandes retornos futuros, si es que los beneficiarios futuros van a estar en una situación mejor que la generación presente. Y por tanto, no requiere ni siquiera sacrificios menores de la generación presente para obtener enormes ganancias para las generaciones futuras, si las generaciones futuras están en una situación un poco mejor que la nuestra.

Hay otros dos enfoques de la responsabilidad intergeneracional que merecen ser mencionados. El primero es un marco general utilitarista. En este enfoque, quienes toman las decisiones adoptarán primero todos los proyectos que tengan una razón costo-beneficio positiva. Y luego, si la distribución resultante fuera poco atractiva, buscarán una forma de redistribución.

Por último, la justicia correctiva requiere que quienes son responsables de la degradación ambiental mitiguen los efectos adversos. En términos económicos, establece la obligación de internalizar el comportamiento ambiental, obligando a las personas a remediar los daños ambientales que producen, y reduciendo el impacto de las externalidades en el proceso de adopción de decisiones. En términos morales, esto implica reconocer que los agentes son responsables por las consecuencias previsibles de sus acciones y deben tener en cuenta el daño que les ocasionan a los demás.

Un marco completo para la distribución intergeneracional probablemente involucre algunos aspectos del desarrollo sustentable, utilitarismo y justicia correctiva. En el contexto intrapersonal, el uso de la tasa de descuento se origina en el respeto a las preferencias individuales. En el contexto intergeneracional, por el contrario, es el resultado de 
nuestro deseo de evitar decisiones difíciles sobre nuestras obligaciones para con los otros, o peor, de nuestro deseo de evitar deberles demasiado a los demás. No tomar una decisión es una decisión en sí misma; y en este contexto, es la decisión incorrecta.

\section{REFERENCIAS}

Ackerman, Frank y Lisa Heinzerling (2004): Priceless: On Knowing the Price of Everything and the Value of Nothing. The New Press.

Adler, Mathew y Eric Posner (2006): New Foundations of Cost-Benefit Analysis. Cambridge: Harvard University Press.

American Heart Association: "La Aspirina en la Prevención de Derrames Cerebrales y Ataques Cardíacos”. http://www.americanheart.org/presenter.

Andrews, Edmund L. (2003): "Liberty and Security: New Scale for Toting Up Lost Freedom vs. Security Would Measure in Dollars”. New York Times, 11 de marzo de 2003, A13.

Arrow, Kenneth (1950): "Difficulty in the Concept of Social Welfare”. En The Journal of Political Economy Vol. 58, No 4. jhtml?identi? er=4456.

Berns, Gregory et al. (2005): “Neurobiological Substrates of Dread”. En Science Vol. 312, $\mathrm{N}^{\circ} 5774$.

Burtraw, Dallas y Michael Toman (1998): "The Benefits of Reduced Air Pollutants in the U.S. from Greenhouse Gas Mitigation Policies”. Discussion Paper No 98-01, Resources for the Future.

Burtraw, Dallas et al. (2001): “Ancillary Benefits of Reduced Air Pollution in the United States from Moderate Greenhouse Gas Mitigation Policies in the Electricity Sector”. Discussion Paper No 01-61, Resources for the Future.

Carson, Richard et al. (2003): "Contingent Valuation and Lost Passive Use: Damages from the Exxon Valdez Oil SIPI”. University of California at San Diego, Economics Working Paper Series 95-02, Department of Economics, UC San Diego.

Cross, Frank (1989): “Natural Resource Damage Valuation”. En Vanderbilt Law Review Vol. 42.

Elliott, Donald (1994): “TQM-ing OMB: Or Why Regulatory Review Under Executive Order 12,291 Works Poorly and What President Clinton Should Do About It”. En Law and Contemporary Problems Vol. 57, № 2.

Ely, John (1980): Democracy and Distrust: A Theory of Judicial Review. Cambridge: Harvard University Press.

Farnsworth, Clyde (1981): “Move to Cut Regulatory Costs Near”. Times, 14 de febrero de 1981.

Field, Bary y Martha Field (1997): Environmental Economics: An Introduction. Irwin/ McGraw-Hill.

Graham, John y Jonathan Wiener (1995): “Confronting Risk Tradeoffs”. En John D. Graham \& Jonathan Baert Wiener (eds), Risk versus Risk: Tradeoffs in Protecting Health and the Environment. Harvard University Press. 
Holmes, Stephen y Cass Sunstein (2000): The Cost of Rights: Why Liberty Depends On Taxes. New York. W. W. Norton \& Company, Inc.

Johannesson, Magnus et al. (1996): "The Value of Private Safety versus the Value of Public Safety”. En Journal of Risk and Uncertainty Vol. 13(3).

Kaiser, Jocelyn (2000): “Soaking Up Carbon in Forests and Fields”. En Science Vol. 290, $\mathrm{N}^{\circ}$ 5493, pp. 922.

Kelman, Steven (1981): “Cost-Benefit Analysis: An Ethical Critique”. En Journal on Government and Society Regulation, enero/febrero, pp. 33-40.

Kennedy, Duncan (1981): “Cost-Benefit Analysis of Entitlement Problems: A Critique”. En Stanford Law Review Vol. 33.

Lave, Lester (1981): The Strategy of Social Regulation: Decision Frameworks for Policy. Washington, DC: The Brookings Institution.

Lutter, Randall (1999): “Is EPA’s Ozone Standard Feasible?”. En AEI-Brookings Joint Center Regulatory Analysis No 99-6. Disponible en http://aei-brookings.org/admin/ authorpdfs/redirect-safely.php?fname=../pdffiles/reg_analysis_99_06.pdf.

Magnuson, Ed (1983): “Three Steps Forward, Two Back”. Time, 29 de agosto de 1983.

Marx, Karl (1867): Capital Vol. 1: A Critique of Political Economy. Pelican Books.

Menell, Peter y Richard Stewart (1994): Environmental Law and Policy. Boston, Little, Brown and Company.

Meyers, Garry y Simone Muller (1996): “The Ethical Implications, Political Ramifications and Practical Limitations of Adopting Sustainable Development as National and International Policy”. En Buffalo Environmental Law Journal Vol. 4.

Miller, Judith (1979): "Report by a Nader Group Measures Dollar Benefits of U. S. Regulations, Professor Defends Study”. New York Times, 10 de octubre de 1979.

Olson, Erik (1984): “The Quiet Shift of Power: Office of Management \& Budget Supervision of Environmental Protection Agency Rulemaking Under Executive Order 12,291”. En Virginia Journal of Natural Resources Vol. 4, № 1.

Pildes, Richard y Cass Sunstein (2005): "Reinventing the Regulatory State". En University of Chicago Law Review Vol. 62.

Piper, Steven y Jonathan Platt (1998): "Benefits from Including Wetland Component in Water Supply Projects”. En Journal of Water Resources Planning and Management Vol. 124, No 4 (julio/agosto).

Revesz, Richard y Michael Livermore (2008): Retaking Rationality: How Cost Benefit Can Better Protect the Environment and Our Health. New York: Oxford University Press.

Scarry, Elaine (1996): “Speech Acts in Criminal Cases”. En Peter Brooks \& Paul Gewirtz (eds.), Law's Stories: Narrative and Rhetoric in the Law, Yale University.

Shane, Peter (1995): "Political Accountability in a System of Checks and Balances: The Case of Presidential Review of Rulemaking”. En Arkansas Law Review Vol. 4.

Shelef, M. (1994): "Unanticipated Benefits of Automotive Emission Control: Reduction in Fatalities by Motor Vehicle Exhaust Gas”. En Science of the Total Environment, Vol. 146/147.

Simons, Robert y Kimberly Winson-Geideman (2005): “Determining Market Perceptions on Contamination of Residential Property Buyers using Contingent Valuation Surveys”. En Journal of Real Estate Research Vol. 27(2).

Sinden, Amy (2005): "In Defense of Absolutes: Combating the Politics of Power in Environmental Law”. En Iowa Law Review Vol. 90. 
Skrycki, Cindy (2003): “Under Fire, EPA Drops the 'Senior Death Discount””. Washington Post, 13 de mayo de 2003.

Solow, Robert (1993): “An Almost Practical Step Toward Sustainability”. En Resources Policy Vol. 19(3).

_ (1996): “Health-Health Tradeoffs”. En University of Chicago Law Review Vol. 63.

Sunstein, Cass (2006): “Willingness to Pay Versus Welfare”. En AEI-Brookings Working Paper $\mathrm{N}^{\circ}$ 06-38. Disponible en http://aei-brookings.org/admin/authorpdfs/ redirect-safely.php?fname=../pdffiles/RP06-38_topost.pdf.

Tolley, G. et al. (1994): Valuing Health for Policy. An Economic Approach. Chicago: The University of Chicago Press.

Viscusi, W. (1992): Fatal Tradeoffs: Public And Private Responsibilities For Risk. Oxford University Press.

Weidenbaum, Murray (1975): “The High Cost of Government Regulation”. En Business Horizons Vol. 18 (4), pp. 43-51. Disponible en: http://www.sciencedirect.com/ science/article/B6W45-4DTT2D0-8H/2/7cb563e864a440bd75a1375d27eec59c. (1979): “The High Cost of Governmental Regulation”. En Challenge, nov.dic. 1979.

Weidenbaum, Murray y Robert DeFina (1978): The Cost of Federal Regulation of Economic Activity. Washington D. C.: American Enterprise Institute.

Weiss, Edith (1988): In Fairness to Future Generations: International Law, Common Patrimony, and Intergenerational Equity. Hotei Publishing. (1991): Intergenerational Equity: A Legal Framework for Global Environmental Change, in Environmental Change and International Law: New Challenges and Dimensions. Edith Brown Weiss ed.

Woodward, Bob y David Broker (1991): “Quayle’s Quest: Curb Rules, Leave No Fingerprints”. Washington Post, 9 de enero de 1991, A1.

World Commission on Environment and Development (1987): Our Common Future. Oxford: Oxford University Press. Disponible en http://www.worldinbalance.net/ agreements/1987-brundtland.html. 